\title{
Emancipação política e a luta pelo direito à cidade
}

\author{
Ada Kallyne Sousa Lopes ${ }^{1}$ \\ https://orcid.org/0000-0001-7586-6798 \\ ${ }^{1}$ Universidade de Brasília, Departamento de Serviço Social, Programa de Pós-Graduação em Política Social, Brasília, DF, Brasil
}

\section{Emancipação política e a luta pelo direito à cidade}

Resumo: O presente texto busca apreender o solo histórico onde se processa a luta pelo direito à cidade no Brasil e os limites postos por estas determinações histórico-estruturais à emancipação política da cidade. Trata-se de um trabalho de natureza teórica que, por meio de uma revisão bibliográfica, procurou construir uma interlocução com importantes teóricos da formação social brasileira, a fim de elucidar os entraves e os desafios à plena materialização do direito à cidade em um país de capitalismo de natureza dependente, como o Brasil. Como resultado compreendemos que a luta anticapitalista torna-se vital para a materialização real de cidades mais democráticas, justas e sustentáveis, uma vez que a luta urbana deve ter como horizonte, além da conquista de sua emancipação política - fundamental em sociedades desiguais como a brasileira - a adoção de uma direção crítica socialmente referenciada nas necessidades da classe trabalhadora para a construção de uma nova ordem societária.

Palavras-chave: Questão urbana. Capitalismo dependente. Direito à cidade. Emancipação política.

\section{Political emancipation and the struggle for the right to the city}

Abstract: This article seeks to understand the history of the struggle for the right to the city in Brazil and the limits placed by historicalstructural determinations to the political emancipation of the city. It is a theoretical study using a bibliographical review of the relevant scholars with a background in social sciences to reflect and elucidate the obstacles and the challenges to the full materialization of the right to the city in a country of dependent capitalism, such as Brazil. As a result, it was possible to understand that the anti-capitalist struggle becomes vital for the real materialization of democratic, just, and sustainable cities. The urban struggle must intend, beyond the conquest of political emancipation (fundamental in unequal societies such as Brazil's), to adopt a socially driven critical directions when providing for the needs of the working class and in building a new social order.

Keywords: Urban issue. Dependent capitalism. Right to the city. Political emancipation.

Recebido em 01.06.2018. Aprovado em 18.09.2018. Revisado em 14.12.2018.

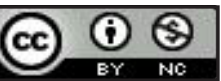

(C) O(s) Autor(es). 2019 Acesso Aberto Esta obra está licenciada sob os termos da Licença Creative Commons Atribuição-NãoComercial 4.0 Internacional (https://creativecommons.org/licenses/by-nc/4.0/deed.pt_BR), que permite copiar, distribuir e reproduzir em qualquer meio, bem como adaptar, transformar e criar a partir deste material, desde que para fins não comerciais e que você forneça o devido crédito aos autores e a fonte, insira um link para a Licença Creative Commons e indique se mudanças foram feitas. 


\section{Introdução}

Este trabalho tem por objetivo apreender os entraves histórico-estruturais para a plena materialização do direito à cidade no Brasil, a partir da construção de um diálogo com as interpretações de Florestan Fernandes e Octávio Ianni sobre o processo de consolidação do sistema capitalista no País, e de como esses condicionantes estruturam os limites e as possibilidades da emancipação política da classe trabalhadora brasileira. Em outras palavras, busca-se compreender o solo histórico onde a luta pelo direito à cidade se processa, seus limites nos marcos do capitalismo dependente e suas particularidades próprias da formação sócio-histórica brasileira. Parte-se do pressuposto de que o debate em torno da questão urbana não deve se ater apenas a discussões tecnicistas e gerencialistas, mas, sim, a fundamentos de ordem estrutural.

Dessa forma, empreendemos uma análise das determinações estruturais da formação do capitalismo no Brasil que conformam, ao mesmo tempo, as possibilidades internas do enfrentamento à questão urbana e os limites e desafios à luta coletiva pela emancipação política da cidade no Brasil atual.

\section{O desenvolvimento desigual e combinado e as particularidades da questão urbana brasileira}

Como salientado por Ianni (1992), a compreensão das determinações históricas, políticas, econômicas e sociais que dão forma ao Brasil atual perpassa pelo entendimento de que o hoje é fruto de um processo de rupturas e continuidades com o passado. Em outras palavras, na análise das relações sociais, a história não deve ser considerada como um processo linear, onde os acontecimentos se desenvolvem de forma autônoma, sem influência nos fenômenos posteriores; mas como um movimento em que se entrelaçam passado e presente.

A pobreza urbana, a falta de saneamento nas cidades, a desigualdade no acesso à terra urbana, os problemas habitacionais e a falta de condições mínimas para uma moradia digna são questões que marcam o cotidiano das cidades brasileiras, e que possuem, a nosso ver, elementos histórico-estruturais que os explicam. Portanto, a análise das determinações que condicionam as possibilidades internas do Brasil mostra ser um fecundo caminho teórico analítico para buscarmos compreender a complexidade da dinâmica urbana brasileira nesse início de século.

A organização e reinvenção das cidades brasileiras atuais possuem um solo histórico rico em elementos a serem examinados, uma vez que "[...] toda a sua história está contida no seu presente, como se fosse um país que não abandona nem esquece o pretérito, memorioso". (IANNI, 1992, p. 63). Lançar mão dessa ferramenta irá contribuir para o distanciamento de uma análise tecnicista e gerencialista dos problemas urbanos. Pois, não comungamos com a assertiva de que estrutura interna das cidades do capital dependente se resume a problemas de gestão ou situam-se no campo das individualidades dos citadinos, mas, sim, de um complexo emaranhado de fatores estruturais internos e externos e, é na busca pela apreensão das particularidades históricas brasileira que iremos nos deter nesse item.

Entendemos que para a compreensão da questão urbana brasileira nas primeiras décadas do século XXI torna-se indispensável, em primeiro lugar, a análise da estrutura dependente que condiciona os países latinoamericanos; e, em segundo lugar, o processo de acumulação primitiva no País e a transformação do escravo em força de trabalho livre.

Portanto, partimos do entendimento de que a questão urbana brasileira é indissociável do processo de acumulação primitiva no País, uma vez que esta se apresenta como um de seus desdobramentos. É na passagem do século XIX para o século XX que o Brasil irá vivenciar uma acelerada urbanização, fruto da expansão do setor agrário-exportador e dos setores complementares responsáveis pelo surgimento de uma burguesia industrial, que ocasionará a supressão do campo pela cidade como centro dinâmico sócio-político.

Para que possamos compreender com profundidade a conformação das cidades brasileiras atuais tornase necessário retomarmos, em nossa análise, alguns dos importantes acontecimentos que marcaram a segunda metade do século XIX no Brasil e que, como enfatizado por Ianni (1987), possuem valor explicativo quando são examinados dentro da estrutura e historicidade em que se desenvolveram. Em outras palavras, o resgate desses elementos do passado nos ajuda a compreender as determinações atuais de nosso objeto de estudo, não significando, contudo, que o presente se configure enquanto uma reprodução ampliada do passado.

De acordo com Ianni (1987), a partir da segunda metade do século XIX a sociedade brasileira passou a adquirir uma relativa autonomia e singularidade com as modificações advindas de importantes acontecimentos sociais, tais como a campanha abolicionista, campanha republicana, interrupção do tráfico de escravos, expansão e predomínio da cafeicultura, imigração europeia e colonização de regiões despovoadas. Para o autor, uma das principais marcas desse período - e que se constitui enquanto solo histórico desses fatos - foi a coexistência de uma produção mercantilizada associada a um regime escravocrata. 
Com o desenvolvimento das forças produtivas e com o surto de expansão econômica ocasionada pelo crescimento do setor agrário-exportador e do setor urbano industrial, o antagonismo entre mercadoria e escravo começou, de acordo com Ianni (1987), a tornar-se incompatível com as condições sócio-históricas necessárias para a plena solidificação do capitalismo no País, exigindo, assim, modificações substanciais no sistema social vigente.

Conforme Ianni (1987) e Fernandes (1976), o processo de consolidação das transformações capitalistas no Brasil apresentou crises de diferentes profundidades. Logo, com a inserção do País em um novo ciclo de desenvolvimento econômico, uma das mais significativas crises foi provocada pela necessidade de superar o antagonismo entre mercadoria e escravo. Ou seja, para a edificação de uma estrutura interna em consonância com uma economia estritamente capitalista, os agentes econômicos necessitavam romper com a contradição fundamental desse período, convertendo, portanto, o escravo em trabalhador livre, disponível para vender sua força de trabalho em troca de um salário.

Dessa forma, para Ianni (1987), a contradição que se apresenta enquanto mercadoria e escravo no plano econômico, e escravidão e liberdade no plano ideológico, vai sendo superada por meio da racionalização do modo de produção difundido pelas relações de produção e pela execução de arranjos jurídicos e políticos que tornam o escravo em trabalhadores livres, detentores legais da posse de sua força de trabalho.

De acordo com Ianni (1987) é a cidade o grande centro político, econômico e cultural que irá aglutinar todas essas contradições. Para o autor, é nas cidades brasileiras do século XIX que o antagonismo entre mercadoria e escravo ganha significação social e política, uma vez que é no espaço urbano, enquanto fruto de um novo estágio de desenvolvimento do processo de acumulação capitalista em que "[...] a hegemonia urbana e metropolitana aparece, desse ângulo, como subproduto da hegemonia do complexo industrial-financeiro" (FERNANDES, 1976, p. 297), que as bases morais e políticas do regime escravocrata são postas em xeque.

Ainda em relação às elaborações de Ianni (1987) sobre este processo, o autor nos revela que é na cidade o lugar onde o escravo representa um sistema econômico e político que necessita ser ultrapassado, sem, contudo, ser eliminado. Ou seja, apesar da transformação do escravo em trabalhador livre representar possibilidades de ampliação nas margens de lucro do sistema produtivo, a estrutura social ainda era fortemente marcada pela opressão dos negros, uma vez que estes "[...] viveram dentro da cidade, mas não progrediram com ela e através dela". (IANNI, 1987, p. 44).

Dessa forma, a redefinição social do trabalho produtivo apresentou importantes modificações com a finalidade de construir as condições internas necessárias para a plena consolidação das relações capitalistas. As cidades representam, portanto, o centro desse processo ao ser o berço onde se materializavam significativas mudanças tanto no âmbito social, político quanto no econômico com a abolição da escravatura, a consolidação de uma economia urbana industrial e comercial e a naturalização de imigrantes para o trabalho assalariado nas lavouras de café.

A particularidade da organização espacial das cidades brasileiras possui a marginalização como uma de suas marcas indeléveis, desde sua origem, da população negra que, como salientado por Ianni (1987), passou da condição de ex-escravo para a de classe trabalhadora livre. É importante enfatizar que, como destacado por Moura (2014), os negros ao tornarem-se trabalhadores livres foram duramente discriminados com a implementação da política de branqueamento vigente nesse período, em que os agentes econômicos incentivavam a entrada de imigrantes no País para ocupar os postos de trabalho, enquanto os escravos formavam o exército industrial de reserva.

Logo, temos uma cidade formada por ex-escravos, agora trabalhadores livres expropriados de qualquer forma de subsistência, que passam a ocupar de forma desordenada o espaço urbano, e por trabalhadores parcialmente inseridos no processo produtivo, seja ele urbano industrial ou agrário, que passam a viver em cortiços e em habitações precárias, além de grandes empresários e uma elite burguesa nacional que direcionam o planejamento e desenvolvimento urbano dessas cidades.

Para Fernandes (2008), para a compreensão sobre a formação do capitalismo urbano industrial e comercial, é necessário levarmos em consideração as profundas influências que o capitalismo agrário terá nesse processo, que irá gerar conforme o autor, um caráter duplamente articulado da economia brasileira denominado por Fernandes (2008) de "[...] uma dependência dentro da dependência".

Um aspecto sinalizado por Fernandes (1976) em suas análises sobre a formação do capitalismo dependente no Brasil é o da íntima relação entre as transformações capitalistas e o padrão de dominação burguesa nas sociedades de economia periférica. Para o autor, a dominação burguesa nesses países compõe interesses de classe extra-burgueses e burgueses - tanto internos quanto externos - no conjunto de modificações operadas no âmbito econômico, sociocultural e político.

Fernandes (2008) assinala que o capitalismo como modo de produção hegemônico se manifestou de forma tardia na evolução econômica e histórico-social do Brasil, uma vez que este não estava germinado no sistema colonial e apenas se expandiu com a desintegração do sistema de produção escravista. Um importante 
elemento debatido pelo autor para a caracterização dessas transformações é a real liberdade que os agentes econômicos nacionais possuíam para concretizar essas mudanças sociais necessárias para a consolidação do capitalismo enquanto modo de produção hegemônico.

Segundo o autor, a liberdade efetiva desses agentes representava a negação da própria liberdade, na medida em que os vínculos estabelecidos pela estrutura dependente entre as economias centrais e a periférica brasileira perpetuavam a heteronomia econômica, uma vez que os agentes econômicos internos se tornavam instrumentais para a consolidação dos interesses dos agentes econômicos dominantes. Entretanto, Fernandes (1976) assinala que apesar da burguesia brasileira manter uma relação de dependência com as elites dominantes externas, esta possuía internamente um forte poder político, econômico e social, além de deter o controle da máquina estatal nacional.

Em consonância com Fernandes (2008), nos marcos do desenvolvimento econômico brasileiro, a expansão e afirmação de uma economia de mercado especificamente capitalista tiveram como principais beneficiários os setores ligados à economia urbana industrial e comercial. Assim, a eclosão de um sistema produtivo predominantemente capitalista não provocou fortes efeitos na economia agrária brasileira, uma vez que sua relação com a economia interna e externa manteve-se inalterada.

Essa inalteração da economia agrária ocorreu, de acordo com Fernandes (2008), por meio de inúmeras pressões de agentes econômicos ligados ao setor urbano industrial e comercial. Pois, a expansão dos polos urbanos modernos necessitava permanentemente da transferência de excedentes econômicos do setor agrário exportador "[...] organizando uma verdadeira drenagem persistente das riquezas produzidas no campo em direção das cidades com funções metropolitanas". (FERNANDES, 2008, p. 174).

Essa estrutura de dependência entre os agentes econômicos internos com sua orientação urbana ou rural irá conformar o que Fernandes (2008) denominou de dependência dentro da dependência, uma vez que a economia agrária foi convertida em meio necessário para a materialização de diferentes fins econômicos, por meio da drenagem do excedente econômico, tanto na direção das cidades como para o mercado externo. Para o autor, essa dupla articulação da economia brasileira ocasionou um atrofiamento da economia agrária e a eclosão de uma hegemonia da economia urbana industrial e comercial que se traduz pela intensificação do desenvolvimento capitalista no espaço urbano.

Existe, para Fernandes (2008), um entrelaçamento entre os interesses dos agentes econômicos internos urbanos e rurais. Ou seja, o padrão de dependência dentro da dependência tornou-se vantajoso para o setor empresarial e para as elites econômica privilegiadas. E, mesmo não beneficiando diretamente o setor agrárioexportador, essa dinâmica de transferência de excedente econômico não perturbava os empresários rurais, uma vez que buscavam resguardar sua posição e status social.

A interdependência entre as elites econômicas nacionais, de acordo com Fernandes (1976), representa a luta travada pela burguesia nacional por sua sobrevivência e pela sobrevivência do capitalismo. Conforme Ianni (1992), todas essas injunções econômicas, políticas e sociais destacadas por Fernandes (1976, 2008) levam a burguesia brasileira a acomodar-se e associar-se, seja em relação aos interesses da burguesia externa ou em relação à dependência interna entre burguesia urbana e rural.

O debate sobre o processo da revolução burguesa no Brasil é caracterizado por Fernandes (1976) como atípico, visto que não ocorreu aqui, uma simples e automática repetição das determinações que conformaram as revoluções burguesas nas sociedades capitalistas centrais. Ao se materializar por um caminho que excluía qualquer possibilidade de repetição do processo realizado pela via clássica, a revolução burguesa no Brasil ocorreu por uma via alternativa, denominada pela literatura de via prussiana ${ }^{1}$.

Ianni (1984) enfatiza que a revolução burguesa brasileira à prussiana indica que a passagem para o capitalismo no País ocorreu sem mudanças substanciais na estrutura agrária. Dessa forma, para o autor, a concretização desse processo no Brasil representou uma conciliação de classes pelo alto - de frações das classes dominantes - em que as classes e camadas sociais pertencentes à classe trabalhadora foram reprimidas e marginalizadas. Ianni (1992, p. 69) nos apresenta com maestria o caráter da burguesia interna brasileira:

Essa burguesia, portanto, não avançou nem avança para um projeto político alternativo para a sociedade nacional. Não vai além da própria visão de setor de classe e cooperação. Joga com as outras classes sociais de modo tímido, pouco elaborado. Teme a força política dessas classes, principalmente o risco de ter de compartilhar o poder. Assusta-se com as ideias de reformas sociais [...]. Não tem compromisso com a democracia reivindicada nas lutas das classes assalariadas. Não construiu nem constrói um projeto de cunho hegemônico, porque não interpreta os interesses das outras classes e muito menos das sociedades como um todo. Apenas defende os próprios interesses corporativos. Quando se sente ameaçada pelo imperialismo, apela às "massas". E quando é desafiada pelos setores assalariados e camponeses, organizados e ativos, corre aos quartéis e às embaixadas das nações imperialistas. 
Em suas análises, Fernandes (1976) destaca que a revolução burguesa - condicionada pelos interesses externos de um capitalismo maduro - apesar de não ter alterado substancialmente a estrutura agrária no Brasil, esteve vinculada a alterações estruturais e dinâmicas em diferentes setores produtivos e na própria estrutura social do País. As transformações capitalistas necessitavam de uma forte dominação burguesa interna. Nas palavras do autor, "[...] o capitalismo dependente e subdesenvolvido é um capitalismo selvagem e difícil, cuja viabilidade se decide, com frequência, por meios políticos e no terreno político”. (FERNANDES, 1976, p. 293).

Essa característica do capitalismo dependente imprime, de acordo com Fernandes (1976), um padrão singular de dominação burguesa nos países periféricos. É uma dominação em que há uma hipertrofia dos fatores sociais e políticos. Em linhas gerais, tanto Fernandes (1976) quanto Ianni (1984) assinalam a necessidade de a burguesia interna capturar a máquina estatal e exercer um poder político forte para saturar todas as funções políticas essenciais para a materialização da dominação burguesa.

Um importante elemento para a dominação burguesa, sinalizado por Osório (2014) e retomado por autores como Ianni (1984, 1992) e Fernandes (1976), é a exigência de um Estado nacional forte internamente. De acordo com Ianni (1984), uma das características do Estado brasileiro na história da revolução burguesa foi a predominância de um caráter autoritário.

Em suas análises sobre o autoritarismo estatal brasileiro, Ianni (1984) assinala que a construção desse perfil de Estado foi responsável pelo surgimento da ideia de que a sociedade civil nacional é amorfa e débil. Ou seja, nasce a tese da incompetência da Sociedade Civil em lutar por seus direitos e pela construção de uma emancipação política. Frente a essa tese, Ianni (1984) contra-argumenta que esse ponto de partida teórico perde de vista a história social do povo brasileiro, das revoltas e lutas populares dos movimentos sociais no campo e na cidade.

Ianni (1984) enfatiza que apesar dessas estratégias criadas pela burguesia interna para conseguir materializar as alterações sociais, econômicas, políticas e culturais necessárias para o pleno funcionamento do processo de acumulação capitalista, no País sempre houve movimentos de resistência de grupos e camadas sociais pertencentes à classe trabalhadora, que por meio de organização, consciência e força política lutavam contra sua exploração e em busca de uma maior participação política e conquistas sociais.

As respostas da classe dominante às contradições entre capital e trabalho estão pautadas, de acordo com Fernandes (1976) e Ianni (1984), em uma acentuada violência e repressão policial, que possui no golpe de Estado uma importante ferramenta a ser acessada, assim que houver a necessidade, para assegurar a manutenção de sua dominação interna.

Ianni (1984) nos lembra de que a história da formação social brasileira é marcada por avanços e recuos no processo democrático em que sua trajetória histórica é formada por um caráter restrito, autoritário e antidemocrático com a utilização, pela burguesia interna, de golpes de Estado sempre que se faz necessário a implementação de transformações capitalistas. Esses são exemplos dos golpes citados pelo autor nos anos de 1937, 1945, 1964 e que podemos acrescentar o ocorrido no ano de $2016^{2}$.

Para Ianni (1984) e Fernandes (1976), o padrão de dominação burguesa engendrado pela elite brasileira assegura uma permanente contrarrevolução, em que o despotismo do capital e as potencialidades da dominação são constantemente reformuladas e multiplicadas por meio da associação entre a burguesia interna brasileira e os interesses do capitalismo maduro.

Com base na análise desses elementos que compõem a trajetória política, social e econômica do modelo autocrático burguês de transformação capitalista no Brasil, podemos inferir que estes são marcas indeléveis da formação das cidades brasileiras, desde as metropolitanas até as situadas no interior do País. Pois, compreendemos que, como enfatizado pelos autores, o resgate desses elementos do passado não significa, nunca, sua mecânica repetição histórica. Corroboramos a caracterização de Ianni (1992, p. 61) de que esses processos confluem para a construção de um "Brasil caleidoscópio de vários tempos".

Dessa forma, a dimensão espacial das transformações capitalistas na atualidade está eivada por todos esses elementos que marcaram a formação social do capitalismo dependente no Brasil e que foram destacados por importantes teóricos. Nosso objetivo, ao percorrer esse caminho teórico foi o de desmistificar um errôneo fundamento que persiste em muitas das análises sobre a produção e reprodução das cidades do capital dependente que é a presunção de que elas irão repetir - independente de suas particularidades social e históricas o mesmo percurso e desafios em relação ao desenvolvimento urbano das cidades do capitalismo central.

Em síntese, extraímos dessas análises dois fundamentos que consideramos ser centrais para a compreensão das cidades brasileiras na atualidade. Em primeiro lugar, o peso do processo de acumulação primitiva no País e da transformação do escravo em cidadão livre e, em segundo lugar, o caráter duplamente articulado da economia brasileira responsável pela conciliação entre os diferentes setores da burguesia interna e pela articulação e associação destas com a elite econômica e política dos países centrais, assim como seu padrão de dominação. 


\section{Emancipação política no Brasil atual: contrarreformas, lutas e entraves históricos}

Com a finalidade de nos aproximarmos das determinações que dão forma a nossa questão, percorremos um caminho teórico analítico, que buscou apreender as particularidades da questão urbana brasileira e de sua natureza em uma sociedade dependente e desigual. Dado que compreendemos que os entraves à materialização das conquistas de direitos relativos à cidade são, em sua essência, de ordem histórico-estrutural.

A dualidade entre os direitos urbanos previstos em legislações e o movimento real de produção e reprodução das cidades do capital acaba por mistificar e, em muitos casos, redireciona o debate sobre a questão urbana. Essa passa a ser apreendida enquanto problema de gestão, de falta de aplicabilidade pelos governos municipais, estaduais e/ou federal dos instrumentos urbanísticos previstos em lei. O debate se desloca dos desdobramentos do conflito capital versus trabalho no âmbito urbano para o da inoperância governamental.

É interessante observar que, diferente de outras ex-

[...] entendemos que 0

movimento de luta em prol

das políticas sociais voltadas

para a efetivação do direito à

cidade precisa apreender esse

movimento contraditório da

emancipação política. $\mathrm{Ou}$

seja, na medida em que

mais direitos, esbarramos

cada vez mais nos limites

próprios desse tipo de

emancipação. avançamos na conquista de

pressões da questão social que muitas vezes apresentam uma ausência ou insuficiência de políticas sociais, a política urbana é formada por um expressivo conjunto de leis que trazem em suas letras importantes avanços para a construção de cidades mais justas. Os Artigos Constitucionais 182 e 183 de 1988 fixam um dos mais importantes princípios reivindicados pelo movimento urbano que é a função social da cidade e da propriedade (BRASIL, 1988). O Estatuto da Cidade (BRASIL, 2001) - Lei que se transformou em referência mundial no debate sobre o direito à cidade - traz uma coleção de instrumentos urbanísticos para a materialização de cidades sustentáveis. Temos leis que estabelecem as diretrizes básicas sobre o saneamento básico, mobilidade urbana, resíduos sólidos, regularização fundiária, o estatuto da metrópole, legislação sobre assistência técnica pública e gratuita às famílias de baixa renda para projetos de habitação de interesse social, o Fundo Nacional de Habitação de Interesse Social e Sistema Nacional de Interesse Social, Política Nacional de Desenvolvimento Urbano etc.

Podemos observar que, mesmo com as conquistas de importante marcos legais, as cidades brasileiras continuam estruturalmente desiguais. Essa particularidade da política urbana brasileira em relação às demais expressões da questão social nos proporciona as condições necessárias para retomarmos o debate, realizado por Marx, sobre os limites da emancipação política e a crítica ao fetichismo do Estado político. Porquanto, apesar da luta por mais direitos se tornar indispensável e cada vez mais necessária em países tão desiguais, como o Brasil, em que há uma crescente barbarização da vida social, essa emancipação política possui limites. Logo, as políticas sociais voltadas à garantia do direito à cidade se apresentam, dentre as demais políticas brasileiras, como um fértil campo analítico para debatermos esses limites e compreendermos o significado que plena emancipação política representa nos marcos do capitalismo.

Não figura entre nossos objetivos, ao problematizarmos essa questão, menosprezar ou desmerecer a importância que as conquistas legais, relativas à produção das cidades, têm na melhoria das condições de vida citadina da classe trabalhadora. Na verdade, entendemos e concordamos com a assertiva de que estas representam frutos da luta de classe e das lutas populares empreendidas pelos movimentos sociais, associações populares, organizações não governamentais e instituições de pesquisas, que reivindicam a construção de cidades justas e igualitárias. Nosso propósito é, portanto, buscar compreender os limites que essas conquistas no âmbito legal possuem para interferir de forma concreta na dinâmica real da vida nas cidades.

Vivemos um momento particular na história de nosso País. Como diria Ianni (1992), é um presente que não abandona seu passado, sempre o relembrando com um velho saudosismo - tanto em seus aspectos mais negativos, como também nos positivos com a mobilização e resistência da classe trabalhadora fruto do processo de radicalização da luta de classes. O golpe no governo posto a cabo, em 2016, pela então posição de direita - maior expressão no Partido da Social Democracia Brasileira (PSDB) - e por setores mais reacionários da sociedade brasileira, apesar de apresentar suas particularidades em relação aos golpes de Estado anteriores, faz parte de uma cíclica trajetória de avanços e contínuos recuos no processo democrático brasileiro. 
Analisar o esgotamento da emancipação política no capitalismo dependente e no momento atual do Brasil não é uma tarefa simples. Assim como nos ensina Marx (2010) em sua análise sobre a questão judaica, a emancipação política de sujeitos sociais em relação a uma questão está diretamente relacionada ao tipo de Estado político presente em cada país. Assim, em um Estado que apresenta ao mesmo tempo poder político forte e uma soberania restrita e limitada - como nos casos latino-americanos, por exemplo - esses limites ganham contornos singulares em relação à emancipação política em outros modelos de Estado.

Em sua explanação sobre a questão da emancipação dos judeus na Alemanha, Marx (2010) debate a multiplicidade de formas e contornos que essa questão pode apresentar ao se levar em consideração as diferenciações concretas entre o Estado francês, o estadunidense e o alemão, por exemplo. É bastante conhecido que o pano de fundo dessa construção teórica feita por Marx (2010) é a discussão entre emancipação política e emancipação humana.

Em síntese, Marx (2010) busca com seu texto explorar as barreiras da emancipação política na atual ordem vigente, realizando assim uma sagaz crítica ao Estado político. Não é nosso propósito reproduzir neste trabalho o debate feito por Marx (2010) sobre a emancipação política dos judeus e os limites desta numa sociedade de classes. Na verdade, acreditamos que mais que apenas um debate sobre uma questão específica, Sobre a questão judaica lança importantes fundamentos teóricos para compreendermos, não apenas a questão dos judeus na sociedade, mas também o movimento contraditório que ocorre no processo de absorção, pelo Estado, das demandas e reivindicações populares.

Assim como Marx (2010) elencou uma questão específica para a construção de um debate mais profundo, entendemos que a análise, na realidade brasileira, da luta pela emancipação política da cidade nos proporcionará os elementos necessários para compreendermos os limites que a emancipação política e o Estado político apresentam na garantia de direitos e conquistas para a classe trabalhadora. É incontestável que a emancipação política, em uma sociedade desigual como a brasileira, é um progresso dentro dos marcos do atual sistema vigente. $\mathrm{O}$ que queremos apreender é o movimento contraditório que a emancipação política apresenta em um Estado historicamente autoritário e impositivo.

Como assinalado anteriormente, diferentemente das demais expressões da questão social, os problemas urbanos apresentam um significativo avanço em termos de conquistas legais. Entretanto, apesar desse expressivo aumento no número de legislações que buscam regulamentar o espaço urbano, as cidades brasileiras ainda são marcadas por uma gritante e escancarada desigualdade socioespacial. É a partir desse cenário que nos perguntamos em que medida a emancipação política da cidade é eficaz na garantia de melhores condições de vida da população urbana brasileira?

Para começarmos a compreender essa questão, precisamos interpretar, em primeiro lugar, o que Marx (2010, p. 42) quer nos dizer quando afirma que "[...] a cisão do homem em público e privado [...] não constitui um estágio, e sim a realização plena da emancipação política". Para Marx (2010), o elemento central para entendermos a emancipação política no capitalismo é a apreensão do Estado, pois ele representa o mediador entre o homem e a liberdade do homem.

Em outras palavras, a divisão entre questões públicas e privadas, entre indivíduo e cidadão, passa pelo Estado uma vez que este representa, segundo Marx (2010), o meio pelo qual o indivíduo poderá se libertar politicamente de uma limitação. Para o autor, do ponto de vista estatal todos os indivíduos no âmbito público são apreendidos enquanto cidadãos, livres e iguais.

O Estado, afirma Marx (2010), ao libertar politicamente o indivíduo sobre uma questão, o liberta apenas enquanto cidadão, ou seja, no âmbito público. Esses elementos não serão automaticamente extintos ou libertos na esfera privada da vida dos indivíduos. Dessa forma, o indivíduo passa a viver, de acordo com Marx (2010), uma vida dupla, uma vez que as questões ou limitações sociais emancipadas politicamente continuam subsistindo fora da esfera estatal. Nas palavras do autor:

O Estado político pleno constitui, por sua essência, a vida do gênero humano em oposição a sua vida material. Todos os pressupostos dessa vida egoísta continuam subsistindo fora da esfera estatal na sociedade burguesa, só que como qualidades da sociedade burguesa. Onde o Estado político atingiu a sua verdadeira forma definitiva, o homem leva uma vida dupla não só mentalmente, na consciência, mas também na realidade, na vida concreta; ele leva uma vida celestial e uma vida terrena, a vida na comunidade política, na qual ele se considera um ente comunitário, e a vida na sociedade burguesa, na qual ele atua como pessoa particular, encara as demais pessoas como meios, degrada a si próprio à condição de meio e se torna um joguete na mão de poderes estranhos a ele. (MARX, 2010, p. 44).

É por este motivo que Marx (2010), apesar de apreender a emancipação política enquanto um progresso dentro da ordem mundial vigente, nos chama atenção para que não tenhamos ilusão quanto aos seus limites. 
Para o autor, é pela via dos elementos particulares que o Estado se constitui como universalidade, uma vez que necessita dos pressupostos materiais e espirituais da vida particular.

[...] nos períodos, em que o Estado político é gerado por meio da violência como Estado político a partir da sociedade burguesa, em que a autolibertação humana procura realizar-se sob a forma da autolibertação política, o Estado pode e deve avançar até a abolição da religião, até a destruição da religião; porém, somente na medida em que avance até a abolição da propriedade privada, até o maximum, até o confisco, a taxação progressiva, em que avance até a abolição da vida, até a guilhotina. [...] Nos momentos em que está particularmente autoconfiante, a vida política procura esmagar seu pressuposto, a sociedade burguesa e seus elementos, e constituir-se como a vida real e sem contradição do gênero humano. No entanto, ela só consegue fazer isso caindo em contradição violenta com suas próprias precondições de vida. (MARX, 2010, p. 42).

Dessa forma, para Marx (2010), a libertação política do indivíduo, via Estado, mantém inalterado o antagonismo secular entre interesse geral e interesse particular, ou seja, entre Estado político e sociedade burguesa. Quanto mais o Estado avança em termos de superar a limitada emancipação política, mais este esbarra em seus próprios pressupostos. Portanto, para Marx (2010) a religião, a propriedade privada, a expropriação dos trabalhadores dos meios de produção e dos recursos sociais de produção são elementos materiais que continuarão a existir mesmo com a plena realização de uma emancipação política, pois estes ao serem libertados da esfera pública passam a ocupar a dimensão privada da vida real.

Portanto, o limite da emancipação política da questão urbana no Brasil é apreendido no momento em que, ao mesmo tempo no qual o Estado brasileiro liberta politicamente os sujeitos citadinos em relação ao não acesso ao direito à cidade, criando uma vasta legislação e assegurando conquistas sociais, ele deixa intacto no âmbito da esfera privada - os entraves à materialização desses marcos legais, que na nossa sociedade é representada pela supremacia da propriedade privada, a interdependência entre a burguesia interna urbana e rural, e sua subserviência em relação aos interesses do capital mundializado, assim como o ódio de classe e o descompromisso com os interesses e necessidades da classe trabalhadora.

Diante destas particularidades da formação social, política e econômica da sociedade brasileira é importante assinalar que o próprio Estado - impositivo e autoritário - torna-se um dos entraves à plena emancipação política da classe trabalhadora, uma vez que a divisão entre interesses públicos e privados se torna caricata num Estado capturado pela burguesia interna dependente.

Essa é, a nosso ver, uma das principais contradições que permeiam o processo de conquista da emancipação política da classe trabalhadora nos países de capitalismo dependente. Ou seja, ao passo em que os entraves estão postos dentro do próprio sistema mundial vigente, esta se torna extremamente necessária em democracias blindadas ${ }^{3}$, com Estados fortemente imunes às reivindicações da classe trabalhadora. Portanto, em realidades como a do Brasil, a emancipação política de uma questão representa o resultado de intensas e duras lutas travadas pelos trabalhadores na busca por garantia de seus direitos, o acirramento das contradições sociais dentro da estrutura de dependência torna essa disputa mais brutal que nas sociedades de capitalismo central.

Em uma conjuntura de sucessivos retrocessos e expropriação de direitos sociais - como forma de sustentar os efeitos estruturais da crise do capital - o Brasil, enquanto país que não teve em sua trajetória histórica a existência de um sistema de proteção social consolidado, passa por um processo de barbarização das condições de vida de sua população. A luta por mais direitos é fundamental para garantir as condições mínimas de sobrevivência e qualidade de vida da classe trabalhadora. Entretanto, precisamos compreender que as conquistas civilizatórias nos marcos do capitalismo não são perpétuas, uma vez que estão inseridas na correlação de forças sociais e sofrem avanços e recuos.

Dessa forma, entendemos que o movimento de luta em prol das políticas sociais voltadas para a efetivação do direito à cidade precisa apreender esse movimento contraditório da emancipação política. Ou seja, na medida em que avançamos na conquista de mais direitos, esbarramos cada vez mais nos limites próprios desse tipo de emancipação. A luta, portanto, ao centrar-se na garantia e expansão na promoção de direitos, deve possuir uma clareza enquanto as limitações que essas ações possuem na condução de mudanças estruturais.

Frente às contrarreformas operadas pelo então governo golpista de Michel Temer tais como: a Emenda Constitucional $\mathrm{n}^{\circ}$ 95, que regulamenta cortes de gastos orçamentários por 20 anos, a contrarreforma Trabalhista, Lei da Terceirização, contrarreforma da Previdência, e o desmonte do financiamento da Seguridade Social (BRASIL, 2016, 2017a, 2017b), para situar apenas as de maior impacto nacional - denominada pelas organizações de luta de pacote das maldades -, os movimentos sociais e entidades que lutam por cidades mais justas e sustentáveis precisam apreender a possibilidade de coexistência da luta por emancipação política e humana, ou seja, ao passo em que num cenário de massiva expropriação secundária a luta 
por direitos é indispensável, ela não deve ser a única emancipação almejada pela classe trabalhadora, pois, os limites dessa emancipação no âmbito urbano já estão traçados na própria dinâmica das estruturas internas do capitalismo no País, como analisamos anteriormente.

\section{Considerações finais}

A luta anticapitalista torna-se vital para a materialização real de cidades mais democráticas, justas e sustentáveis. A luta urbana deve ter como horizonte, além da materialização das conquistas civilizatórias previstas em lei, a adoção de uma direção crítica socialmente referenciada nas necessidades da classe trabalhadora. A sua formação política e a construção de sua agenda de luta não pode se abster de enfrentar teoricamente, os entraves e desafios encarados na prática cotidiana na produção das cidades brasileiras.

Se a formação política destas organizações e entidades populares urbanas não partir de bases materiais, das condições e elementos histórico-estruturais que formam as cidades no capitalismo dependente, a luta pela construção de uma cidade justa e sustentável será uma reivindicação vazia de sentido histórico.

Dessa forma, entendemos que o fetiche de que cidades justas e sustentáveis são possíveis nos marcos do capitalismo necessita ser desmistificado. O que não significa mecanicamente o fim da luta por cidades melhores ou a desqualificação da necessidade de emancipação política.

\section{Referências}

BRASIL. [Constituição (1988)]. Constituição da República Federativa do Brasil. Diário Oficial [da] República Federativa do Brasil, Brasília, DF, 5 out. 1988. Disponível em: http://www.planalto.gov.br/ccivil_03/constituicao/constituicao.htm. Acesso em: 15 jan. 2018. BRASIL. [Constituição (1988)]. Emenda Constitucional n 95, de 15 de dezembro de 2016. Altera o Ato das Disposições Constitucionais Trasitórias, para instituir o Novo Regime Fiscal, e dá outras providências. Diário Oficial da União, Brasília, DF, 16 dez. 2016. Disponível em: http://www.planalto.gov.br/ccivil_03/constituicao/Emendas/Emc/emc95.htm. Acesso em: 15 jan. 2018.

BRASIL. Lei $n^{\circ}$ 10.257, de 10 de julho de 2001. Regulamenta os arts. 182 e 183 da Constituição Federal, estabelece diretrizes gerais da política urbana e dá outras providências. Diário Oficial [da] República Federativa do Brasil, Brasília, DF, 11 jul. 2001. Disponível em: http://www.planalto.gov.br/ccivil_03/leis/LEIS_2001/L10257.htm. Acesso em: 15 jan. 2018.

BRASIL. Lei n ${ }^{\circ}$ 13.467, de 13 de julho de 2017. Altera a Consolidação das Leis do Trabalho (CLT), aprovada pelo Decreto-Lei n ${ }^{\circ} 5.452$, de $1^{\circ}$ de maio de 1943 e as Leis $n^{\text {os }} 6.019$ de 3 de janeiro de 1974, 8.036, de 11 de maio de 1990, e 8.212, de 24 de julho de 1991, a fim de adequar a legislação às novas relações de trabalho. Diário Oficial da União, Brasília, DF, 14 jul. 2017a. Disponível em: http:// www.planalto.gov.br/ccivil_03/_Ato2015-2018/2017/Lei/L13467.htm. Acesso em: 15 jan. 2018.

BRASIL. Lei n ${ }^{\circ} 13.429$, de 31 de março de 2017. Altera dispositivos da Lei no 6.019 , de 3 de janeiro de 1974, que dispõe sobre o trabalho temporário nas empresas urbanas e dá outras providências; e dispõe sobre as relações de trabalho na empresa de prestação de serviços a terceiros. Diário Oficial da União, Brasília, DF, 31 mar. 2017b. Disponível em: http://www.planalto.gov.br/ccivil_03/_ato2015-2018/ 2017/lei/L13429.htm. Acesso em: 15 jan. 2018.

DEMIER. F. Depois do Golpe: a dialética da democracia blindada no Brasil. Rio de Janeiro: Mauad X, 2017.

FERNANDES, F. A revolução burguesa no Brasil. 2. ed. Rio de Janeiro: Zahar, 1976.

FERNANDES, F. Anotações sobre o capitalismo agrário e mudança social no Brasil. In: FERNANDES, F. Sociedade de classes e subdesenvolvimento. 5. ed. São Paulo: Global, 2008. p. 171-190.

IANNI, O. Brancos e negros da formação da sociedade. In: IANNI, O. Raças e classes sociais no Brasil. 3. ed. São Paulo: Brasiliense, 1987. p. 11-136.

IANNI, O. O ciclo da revolução burguesa. Rio de Janeiro: Vozes, 1984.

IANNI, O. A ideia do Brasil moderno. São Paulo: Brasiliense, 1992.

MARX, K. Sobre a questão judaica. São Paulo: Boitempo, 2010.

MOURA. C. Dialética radical do Brasil negro. 2. ed. São Paulo: Fundação Maurício Grabois: Anita Garibaldi, 2014.

OSÓRIO, J. O Estado no centro da mundialização: a sociedade civil e o tema do poder. São Paulo: Outras Expressões, 2014.

\section{Notas}

1 De acordo com Ianni (1984), o tipo de modernização conservadora denominada de via prussiana representa o modelo de conciliação pelo alto adotada pelas burguesias internas, em que não há uma introdução de relações capitalistas e de expansão de novos setores produtivos, sem ocorrer uma alteração na estrutura agrária dos países. Para o autor, mantinha-se também inalterada a marginalização da classe trabalhadora. 
2 1937: Golpe que instaurou o Estado Novo no governo de Getúlio Vargas; 1945: Golpe que destituiu Getúlio Vargas do cargo de chefe do Estado; 1964: Golpe que instaurou a ditadura militar no Brasil; e 2016: Golpe que destituiu a presidente Dilma Rousseff e instaurou o governo golpista de Michel Temer.

3 Termo cunhado por Demier (2017).

\section{Ada Kallyne Sousa Lopes}

ada.kallyne@hotmail.com

Mestrado em Serviço Social pela Universidade Federal do Rio Grande do Norte (UFRN)

Doutoranda em Política Social pela Universidade de Brasília (UnB)

\section{UnB}

Campus Universitário Darcy Ribeiro - ICC Norte - Asa Norte

Brasília - Distrito Federal - Brasil

CEP: 70.910-900

\section{Agradecimentos}

Ao Programa de Pós-Graduação em Serviço Social da UFRN pelos ricos e profícuos debates.

Agência financiadora

Não se aplica.

Contribuições dos autores

Não se aplica.
Aprovação por Comitê de Ética e consentimento para participação

Não se aplica.

Consentimento para publicação

Não se aplica.

Conflito de interesses

Não há conflito de interesses. 